\title{
The Effects of Manipulation of Puberty on Growth
}

\author{
Peter A. Lee \\ Penn State College of Medicine, Milton S. Hershey Medical Center, Hershey, Penn., USA
}

\section{Key Words}

Growth hormone - Growth hormone deficiency $\cdot$ Central precocious puberty - Gonadotropin-releasing hormone analogues · Puberty · Idiopathic short stature •

Spontaneous puberty - Congenital adrenal hyperplasia • Aromatase inhibitors - Oestrogen receptor blockers

\begin{abstract}
Short stature in adulthood can be considered as a disability because it can be associated with many difficulties including those of a psychological and social nature. Many factors can influence final adult height such as genetics, the magnitude of growth hormone $(\mathrm{GH})$ secretion, height before puberty, and the onset and duration of puberty. A crucial factor affecting final adult height, however, is the total height achieved during puberty. The combination of $\mathrm{GH}$ and gonadotropin-releasing hormone analogues greatly enhances growth and their separate and combined use for the treatment of $\mathrm{GH}$ deficiency, central precocious puberty and other diagnoses in children and adolescents is discussed in this article.
\end{abstract}

Copyright $\odot 2003$ S. Karger AG, Basel

\section{Introduction}

Short stature in adulthood, following growth failure during childhood and adolescence, can be considered a disability with resulting psychological, social, educational and professional consequences [1]. While growth hormone $(\mathrm{GH})$ therapy in $\mathrm{GH}$-deficient patients and patients with a limited number of other disorders associated with short stature will accelerate growth [2], such therapy may become less effective during puberty. Adult height may still be compromised if catch-up growth has not occurred by the onset of puberty.

Children with untreated, progressive central or peripheral precocious puberty have diminished adult heights even though they are likely to be tall during childhood. Conversely, patients with delayed puberty because of hypogonadism often attain excessive adult heights. Delay of puberty as a result of hypogonadism but not constitutional delay is, therefore, not associated with short stature. Suppression of the pituitary-gonadal axis with gonadotropin-releasing hormone analogues $(\mathrm{GnRHa})$ in the treatment of central precocious puberty (CPP) lowers gonadotropin and sex steroid secretion and results in a preclusion of loss of height potential, the gaining back of lost height potential and an increase in adult height $[3,4]$.

\begin{tabular}{ll}
\hline KARGER & ( ) 2003 S. Karger AG, Basel \\
0301-0163/03/0607-0060\$19.50/0 \\
$\begin{array}{l}\text { Fax +4161306 1234 } \\
\begin{array}{l}\text { E-Mail karger@karger.ch } \\
\text { www.karger.com }\end{array}\end{array}$ & $\begin{array}{l}\text { Accessible online at: } \\
\text { www.karger.com/hre }\end{array}$
\end{tabular}

Prof. P.A. Lee

Department of Pediatrics H085, Penn State College of Medicine

Milton S. Hershey Medical Center, PO Box 850

Hershey, PA 17033-0850 (USA)

Tel. +1 717531 1022, Fax +1 7175316139 ,E-Mail plee@psu.edu 
Diminished growth potential is correlated with skeletal age that is advanced excessively for height. This maturity is a consequence of sex steroid exposure, primarily oestradiol in both sexes [5]. When a child with growth failure, regardless of the cause, begins puberty while she is still significantly short, skeletal age will advance, often precluding catch-up growth. Conversely, if a child begins puberty early or is exposed to significant levels of sex steroid at an early age, skeletal age generally advances at a disproportionately rapid rate so that growth potential is reduced. Based upon this information, it has been hypothesized that combined therapy with GH and GnRHa may preserve or improve the growth potential of children and adolescents with growth disorders.

The total height achieved during puberty, rather than either the duration of puberty or the peak growth velocity, is clearly the crucial factor concerning the impact upon adult height [6]. Thus, before GnRHa are added as a therapy to increase adult height, it should be considered whether prolonging puberty with the likelihood of deceleration of growth rate will result in greater overall height. Delaying skeletal age maturity by removing the sex steroid stimuli will allow more time for growth and over a sufficient period of time, even at a slower growth rate, a greater height may be achieved. The psychosocial impact of delaying puberty as well as the expense, time and effort associated with the medical treatment, must all be considered.

The addition of $\mathrm{GH}$ is based upon the rationale that $\mathrm{GH}$ secretion is diminished because GnRHa removes the sex steroid stimulus of $\mathrm{GH}$ synthesis. GH will increase the growth rate or preclude a reduced growth rate, so $\mathrm{GH}$ treatment in association with GnRHa therapy should also be considered.

The rationale for the use of GnRHa for the treatment of precocious or early puberty has been primarily based upon foreshortened adult height, an outcome of the natural history of untreated progressive CPP. This consequence is part of the phenomenon that pubertal growth decreases in amplitude in a direct relationship with the age of onset of puberty. With early or precocious puberty, the growth spurt is added to the child component of growth, the magnitude of this spurt continuing to decline with age [7].

Adult height positively correlates with growth (height) before the onset of puberty. Ideally, early treatment with $\mathrm{GH}$ to normalize height before the onset of puberty is the best approach for GH deficiency (GHD). Timely onset of treatment for CPP, before growth potential has been reduced, has also been associated with achieving maximum heights [8]. In most of the clinical situations dis-
Table 1. Diagnoses in which GnRHa and GH treatment may be considered

1 Concomitant GHD and CPP

2 GHD without catch-up growth before puberty

3 CPP with reduced growth rates and potential

4 Excessive sex steroid exposure, peripheral precocious puberty (e.g. congenital adrenal hyperplasia) with compromised growth potential or secondary CPP

5 Chronic primary hypothyroidism diagnosed in peripubertal period

6 Turner syndrome with gonadotropin sufficiency

7 Idiopathic short stature with advanced bone age at early puberty

cussed in this review (table 1), however, puberty has begun while short stature persists. It is not clear whether there is a limit to the increase in adult height that can be gained back using GnRHa with or without GH therapy. Height gain can be anticipated only at a relatively slow rate over an extended period of time. The gain with prolonged treatment with GnRHa alone diminishes considerably with advanced skeletal age, usually precluding the continuation of therapy.

Several early reports have suggested that combined therapy with GH and GnRHa will result in greater adult height. It is well known that adult height is influenced by numerous factors involving multiple genetic determinants, the magnitude of GH secretion, height before the onset of puberty, and the onset and duration of puberty. Premature pubertal development results in foreshortened adult height, generally proportional to the earliness and robustness of pubertal maturity. This is a consequence of accelerated skeletal age maturity that exceeds a concomitant acceleration of growth rate, which is accompanied by tall stature for age during childhood. As a result of the impact of reduced sex steroids decelerating skeletal maturity, there is a theoretical advantage to promoting linear growth with $\mathrm{GH}$ with a concomitant delay of skeletal maturation and epiphyseal closure with GnRHa.

This type of combined GH + GnRHa therapy is clearly indicated for patients who have both GHD and CPP. Other diagnoses in which combined therapy may be considered (table 1) would include: patients treated with GH therapy who have not experienced catch-up growth at the time of onset of spontaneous puberty; patients with CPP who have markedly diminished height potential, particularly if they are growing at subnormal growth rates while receiving GnRHa therapy; short children with dramatically accelerated early puberty and skeletal maturation; 


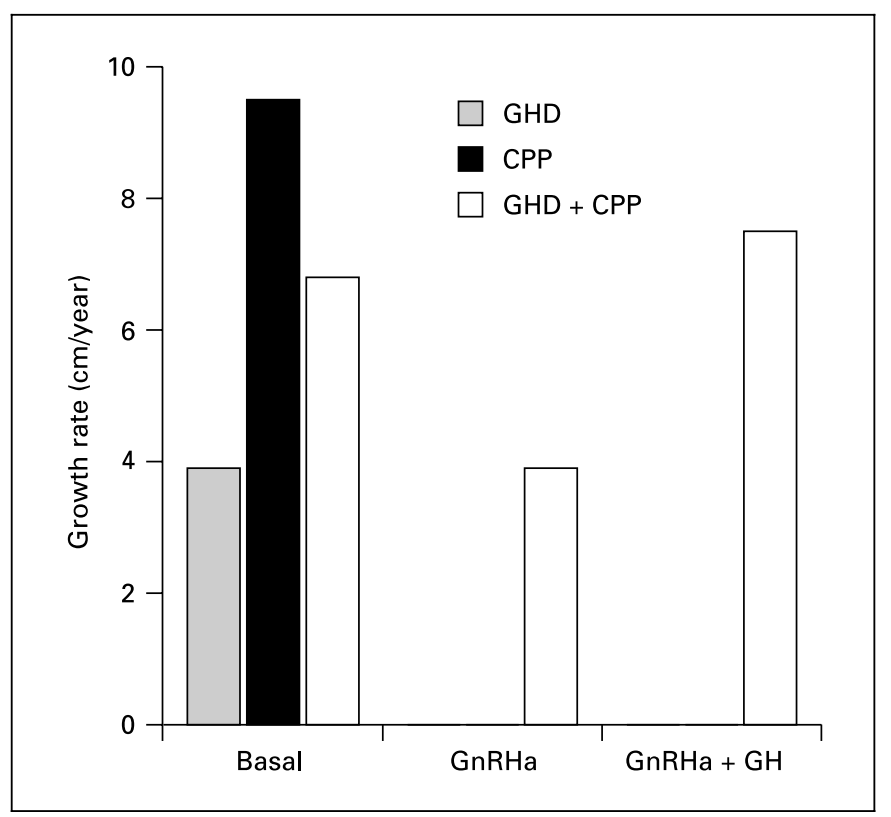

Fig. 1. Pre-treatment growth rates for pre-pubertal GHD, CPP and GHD + CPP. Note that those patients with GHD + CPP have a growth rate greater than those with GHD but less than those with CPP. Treatment of this group with GnRHa alone results in marked deceleration of growth rate, while combination with $\mathrm{GH}$ results in normalization of growth rate. Reproduced, with permission, from Cara et al. [14]: ${ }^{\odot}$ Elsevier, 1992.

pubertal-aged children with undiagnosed chronic primary hypothyroidism; patients with congenital virilizing adrenal hyperplasia and secondary CPP with reduced height and height potential for age; and patients with Turner syndrome with spontaneous pubertal development and persistent short stature.

\section{GHD and Central Precocious Puberty}

In recent years, GHD and CPP have been diagnosed more frequently. This is largely a consequence of successful treatment of malignancy, particularly acute lymphoblastic leukaemia, using radiation and chemotherapy [9, 10]. Recognition of one or other of these diagnoses, more commonly GHD, may be delayed. Growth rates may not diminish because the stimulus, as a consequence of precocious puberty, may override that of the GHD. A substantial growth spurt can occur in patients with CPP and GHD that is dependent on gonadal sex steroid yet unaccompanied by normal pubertal levels of circulating $\mathrm{GH}$ and insulin-like growth factor I [9].
Data suggest that the earlier puberty begins among GH-deficient patients, the shorter will be the height outcome. GH-deficient patients who have spontaneous puberty attain a shorter adult height than gonadotropin-deficient patients [11]. The primary reason for this appears to be that exposure to sex steroids and puberty occurred later in the gonadotropin-deficient group, allowing more time for growth. The GH-deficient group had not only a shorter duration of puberty, but also a smaller pubertal height gain.

A subgroup of patients with spontaneous puberty was treated in the 1980s with either cyproterone acetate or medroxyprogesterone acetate to suppress gonadal steroids [11]. Adult height among these patients was significantly taller (approximately -2.0 vs $>-3.0$ standard deviations [SD]) compared with the height of participants not receiving such therapy, but was still low. The relatively poor outcome may be, in part, a consequence of incomplete suppression of gonadal steroids. At the present time, GnRHa therapy is the treatment of choice for gonadal suppression and, with proper dosing, complete suppression can be achieved.

There were early reports of combined $\mathrm{GH}+\mathrm{GnRHa}$ therapy among patients with CPP and GHD who had had acute lymphoblastic leukaemia and had been treated with radiation and chemotherapy - a common cause of these diagnoses $[12,13]$. The rate of skeletal age maturity slowed to a greater degree with combined therapy while height SD score (SDS) improved for bone age (BA), suggesting greater growth potential [12]. Four years of combined treatment resulted in improvement of height SDS for BA from -0.97 to +0.07 [13].

Combined therapy is appropriate for these two conditions, GH being indicated for GHD and GnRHa for CPP. Outcome data concerning adult height relates to the timing of the diagnosis and therapy. It has been demonstrated, as expected, that therapy with GnRHa alone results in an excessive deceleration of growth rate, while normal or accelerated (catch-up) growth was observed after the addition of GH therapy [14]. Over time, there was a progressive increase in the accuracy of height prediction, the magnitude of the effect of combined therapy being around three times that with GnRHa alone (fig. 1). Although height prognosis was improved, it was less than expected. Ideal onset of both therapies, however, which generally should be concomitant for both $\mathrm{GH}$ and GnRHa, should result in attainment of genetically expected height (within the target height $[\mathrm{TH}]$ range).

The National Cooperative Growth Study (NCGS) registry data for girls with CPP treated using combined GH 
+ GnRHa therapy included a large proportion of patients who were also GH deficient (77\%). In the total group, a significant increase in near-adult height compared with pre-GH treatment predicted adult height $(\mathrm{PAH})$ was found [15]. The total group included patients with and without GHD, so it is not possible to determine what portion of the positive outcome was a result of therapy for GHD versus over-riding the growth rate diminishing effect of GnRHa therapy.

A study was conducted to assess combined ( $\mathrm{GnRHa}+$ GH) treatment among 24 patients with GHD and early puberty, the majority of whom had had cranial irradiation [16]. Outcome data were compared between this group (A), a pubertal group of radiation-induced, GH-deficient, gonadotropin-sufficient patients (B), and a third group with CPP (C). Adult height SDS were $-0.5+0.2,-1.3+$ 0.2 , and $-0.2+0.2$, respectively. Adult heights were significantly lower in the GH-deficient, gonadotropin-sufficient group (B). The conclusion of this study was that treatment with the combination of GH $+\mathrm{GnRHa}$ in patients with GHD and early puberty leads to a normal adult height. Adult heights did not exceed predicted heights at the onset of therapy for groups A or B. This finding may have occurred because the catch-up growth was not realized or the treatment was begun before extensive growth potential was lost. Differences between adult height and PAH correlated positively with the difference between BA and chronological age, negatively with PAH, and positively with the difference between $\mathrm{TH}$ and $\mathrm{PAH}$ at the onset of therapy.

\section{GHD with Gonadotropin Sufficiency (Spontaneous Puberty)}

Many patients with GHD, but spontaneous puberty, fail to attain adult heights within the range of their THs. This may be, in large part, because full catch-up growth has not been realized before the onset of puberty. There is a direct correlation between adult height and both age at onset of GH therapy and height SDS at the start of therapy, and an inverse correlation between adult height and the age at onset of puberty.

GnRHa therapy alone for GHD fails to improve height [17]. A preliminary evaluation of the impact of the addition of GnRHa to GH therapy for 1 year in $10 \mathrm{GH}$-deficient, pre-pubertal and pubertal, boys and girls was performed [18]. Height velocity and BA maturity rates decreased, while height SDS scores for BA increased.

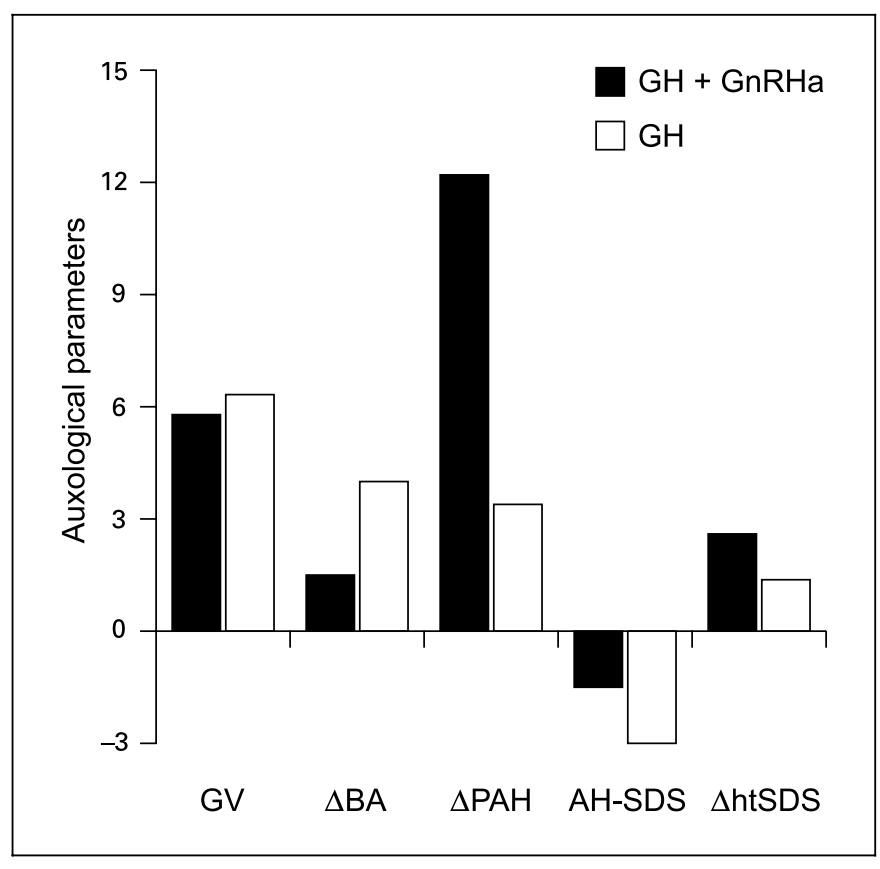

Fig. 2. Mean growth velocity $(\mathrm{GV})$ in $\mathrm{cm} /$ year for 3 years, cumulative change in $\mathrm{BA}$ in years $(\triangle \mathrm{BA})$ and height prediction in $\mathrm{cm}$ $(\triangle \mathrm{PAH})$, near-adult height SDS(AH-SDS) and change in height SDS ( $\triangle$ htSDS) among two groups of GH-deficient patients during 3 years of treatment with $\mathrm{GH}+\mathrm{GnRHa}$ or $\mathrm{GH}$ alone. Mean age at onset of treatment was 14 years. Reproduced, with permission, from Mericq et al. [19]: ${ }^{\odot}$ The Endocrine Society.

In the NCGS data, among girls who had either GHD or idiopathic short stature (ISS) without precocious puberty and were treated with combined therapy, the duration of GH treatment was the most important variable predictive of height gain [15]. This is discussed further below.

A prospective, randomized trial of relatively older GHdeficient children included a GH + GnRHa treatment group and a GH-treated group [19]. Administration of $\mathrm{GH}$ and GnRHa was begun simultaneously in the combined treatment group. Therapy was started between 12 and 17 years of age and all patients were short (mean height SDS, -4.0 ; range, -2.4 to 5.4). Rate of skeletal maturation decreased to a much greater extent in the combined treatment group, resulting in a significantly increased adult height of that group (SDS, $-1.3 \pm 0.5$ vs $-2.7 \pm 0.3$; fig. 2). It is worth noting that the growth rate was sustained better throughout the 3 years of therapy for the combined group, although the GH group started with a greater annual growth rate.

A retrospective study of patients who were started on GH therapy during childhood with the addition of GnRHa at the onset of puberty found that adult heights 
Table 2. Treatment of CPP with GnRHa $+\mathrm{GH}$ or GnRHa alone

\begin{tabular}{lcr}
\hline & GnRHa + GH & GnRHa only \\
\hline Adult height, cm & $160.6 \pm 1.3$ & $157.1 \pm 1.7$ \\
Adult height SDS for BA & $-0.2 \pm 0.2$ & $-0.7 \pm 0.4$ \\
PAH, cm & $152.7 \pm 1.7$ & $152.5 \pm 0.9$ \\
Target height, cm & $155.6 \pm 2.0$ & $155.5 \pm 2.1$ \\
Height gain during study, cm & $7.9 \pm 1.1$ & $1.6 \pm 1.2$ \\
\hline Prior to study & & \\
Growth velocity as SDS for BA & $-3.4 \pm 0.5$ & $-1.0 \pm 0.3$ \\
Height SDS for BA & $-1.5 \pm 0.2$ & $-1.0 \pm 6.3$ \\
PAH, cm & $153.5 \pm 1.7$ & $155.5 \pm 2.0$ \\
\hline During 3-year study & & \\
Growth velocity as SDS for BA & $-2.5 \pm 0.5$ & $-0.1 \pm 0.4$ \\
PAH, cm & $167.1 \pm 3.0$ & $161.5 \pm 2.1$ \\
\hline
\end{tabular}

$\mathrm{BA}=$ Bone age $; \mathrm{PAH}=$ predicted adult height $; \mathrm{SDS}=$ standard deviation score.

Data from Pasquino et al. [23, 24] and Pucarelli et al. [25]: ${ }^{\odot}$ The Endocrine Society and Freund Publishing House.

compared with THs were significantly greater among patients receiving combined therapy than treatment with GH alone, although adult heights were not different [20]. A prospective study was conducted to assess adult height among pubertal males with GHD with GH therapy and after the use of GnRHa in addition to GH therapy [21]. The GH with or without GnRHa portion of this study matched males for $\mathrm{TH}$, age (chronological age) minus BA, height SDS for BA, and PAH at the onset of puberty. Although there were only six males in each group, the results failed to show differences in adult heights $(170.7 \pm$ $9.0 \mathrm{~cm}$ for $\mathrm{GH}+\mathrm{GnRHa}$ vs $173.7 \pm 3.9 \mathrm{~cm}$ for $\mathrm{GH}$ alone), the latter group having reached TH. The second portion of the study compared adult height among males who had attained catch-up growth before the onset of puberty with those who had not. Adult heights (174.2 \pm $4.4 \mathrm{~cm}$ ) from patients treated so that their height SDS were comparable with their $\mathrm{TH}$ percentiles before the onset of puberty suggest that these individuals attain expected adult heights. In contrast, those patients who began puberty before catch-up growth did not reach adult heights $(169.2 \pm 4.3 \mathrm{~cm})$ comparable with their THs. Thus, whenever possible, onset of GH treatment at an early age is clearly more beneficial than temporary delay of puberty. Furthermore, it is unknown whether larger dosages of GH during puberty may lead to results similar to those after combination therapy.

\section{Central Precocious Puberty}

Timely therapy with GnRHa may be sufficient for patients to reach their TH. Attainment of normal adult height within $\mathrm{TH}$ range, with adult height exceeding predicted heights at the onset of therapy, has been demonstrated [16]. Therapy is frequently not ideal, however, and during GnRHa therapy, it may become apparent that some patients will not achieve their THs with GnRHa therapy alone.

Combined therapy for children with CPP who have markedly compromised height predictions or a subnormal growth rate on GnRHa therapy have also been considered as possible candidates for the addition of $\mathrm{GH}$ therapy. Reduced GH secretion can be expected in the pubertal individual after gonadal steroid suppression, with some patients appearing to become relatively $\mathrm{GH}$ deficient [22]. Growth rates progressively decrease during GnRHa therapy, with growth rates for some patients becoming subnormal, but among most patients, growth rates are within the range of a pre-pubertal child. Height predictions increase with therapy as BA matures more slowly than concomitant growth. Growth rates are, however, the slowest among those with more advanced skeletal maturity. In a previous study [22], three girls with reduced growth rates, advanced skeletal ages and subnormal height predictions were found to have decreased levels of GH. Their GnRHa treatment regimen was supplemented with GH and growth rates increased, but less so among the girls with the more advanced skeletal age than among the other patients in the study.

The NCGS registry data for girls with CPP receiving combined therapy indicated a significant increase in near adult height compared with pre-GH treatment PAH [15]. However, as $77 \%$ of these patients also had idiopathic or organic GHD, this report does not address the question of whether GH therapy in addition to GnRHa results in greater adult height in CPP alone.

There are three reports of the same study population of children with CPP, involving two matched groups, one group having received $\mathrm{GH}$ in addition to GnRHa and the second group receiving only GnRHa (table 2) [23-25]. The initial report documented improved growth velocity $(\mathrm{GV})$ for BA (GV SDS for BA) from $-3.4 \pm 0.5$ to $-2.5 \pm$ 0.5 and PAH $(153.5 \pm 1.7$ to $167.1 \pm 3.0 \mathrm{~cm})$ among 10 girls in the group receiving combined therapy after 3 years [23]. For comparison, the 'GnRHa only' treatment group did not have a significantly increased growth velocity for BA (GV SDS for BA) from $-1.0 \pm 0.3$ to $-0.1 \pm 0.4$, while PAH improved $(155.5 \pm 2.0$ to $161.5 \pm 2.1 \mathrm{~cm})$. 
While these two groups were matched for age, BA and duration of GnRHa therapy before enrolment, in GV for BA and PAH at onset appear to be different.

The second and third reports of the study involve adult heights $[23,25]$ after 2-4 years of therapy with GnRHa in addition to GH. Therapy was discontinued in both groups at a skeletal age of about 13 years and the participants were then followed to adult height. The combined group had an adult height that not only exceeded PAH at onset of the study, but also exceeded $\mathrm{TH}$, gaining a mean of $7.9 \mathrm{~cm}$ (fig. 3). The GH-treated group had a mean adult height that was not greater than PAH at onset, although the TH was reached, the mean height gain being $1.6 \mathrm{~cm}$ (table 2). While the comparison groups may not be comparable, because of differences in THs, heights and PAHs at onset of treatment, it appears that the addition of GnRHa therapy will result in more growth, which may even exceed THs. This study appears to demonstrate that among some patients, TH may be reached with GnRHa alone, while the addition of GH may be needed among others. As combined treatment resulted in adult heights that exceeded TH, however, such therapy may not be justified.

Early onset of puberty is frequently observed in children adopted into situations of better socio-economic conditions. Several such children were treated with combined treatment or GnRHa alone [26]. The addition of GH to GnRHa resulted in higher growth velocity and a greater increase in PAH $(10.1 \pm 3.8$ vs $5.7 \pm 3.8 \mathrm{~cm})$ compared with GnRHa therapy alone.

\section{Congenital Adrenal Hyperplasia and Compromised Heights}

Adult heights of patients with classical congenital adrenal hyperplasia are usually compromised, even if they have had reasonable control of adrenal androgen secretion according to accepted monitoring with glucocorticoid suppression. Such reduced growth for skeletal maturation may be a consequence of periodic elevation of adrenal androgens, early or precocious secondary CPP or intervals of over-treatment with glucocorticoids. The former two causes probably stimulate skeletal age maturation to a disproportionately greater degree than concomitant growth, while the latter suppresses both, but primarily suppresses growth rate. To determine whether GH or GH + GnRHa therapy will improve growth, skeletal maturation and thus height prediction, both of these regimens have been used in a 2-year study protocol [27]. Each group

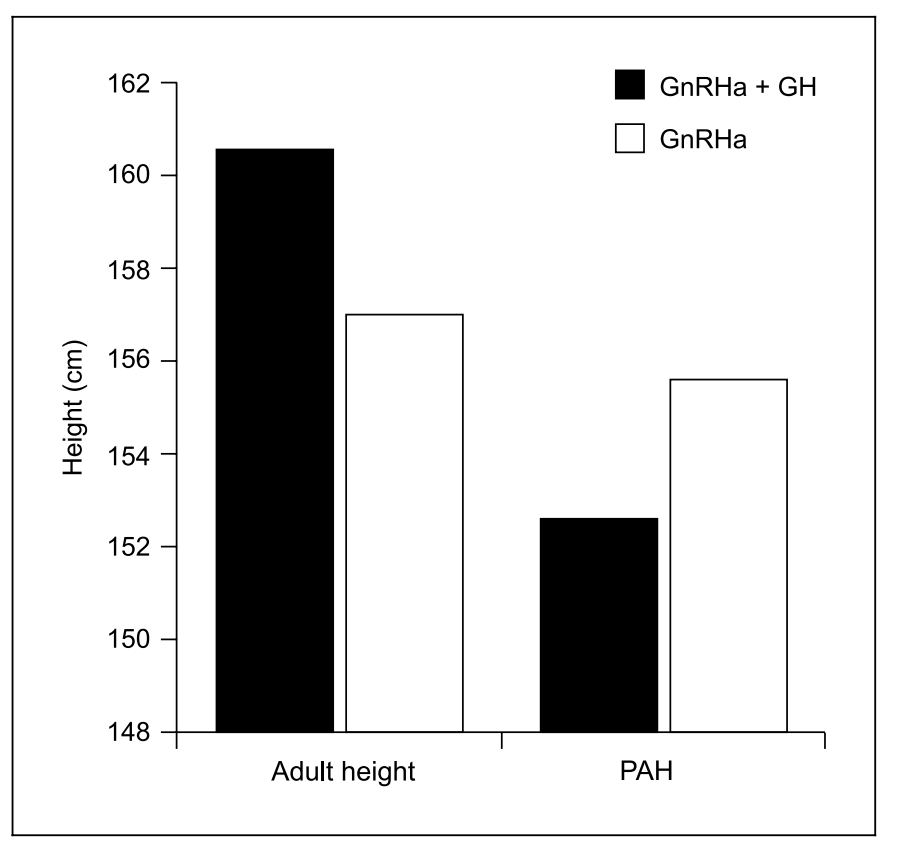

Fig. 3. Comparison of adult heights in relation to $\mathrm{PAH}$ at onset of treatment for two groups of patients with CPP: the group treated with $\mathrm{GH}+\mathrm{GnRHa}$ attained significantly more height.

was matched with a control group for pertinent parameters at the time of the initiation of GH therapy. Height SDS for chronological age and BA both improved significantly more in the treatment than the control groups. Growth rates for chronological age per year, compared with pre-treatment, year 1 and year 2, were $5.1 \pm 1.9$, $8.2 \pm 1.4$ and $7.4 \pm 1.2 \mathrm{~cm} /$ year, respectively, for the patients receiving $\mathrm{GH}$ therapy and $5.0 \pm 1.9,7.3 \pm 1.7$ and $5.2 \pm 1.4 \mathrm{~cm} /$ year, respectively, for those receiving combination therapy. Both control groups had progressively diminishing annual growth rates. Height SDS for skeletal age for the GH group were $-1.9 \pm 0.7$ and $-1.0 \pm$ 0.4 for the first and second year of treatment, respectively, and after combined therapy were $-0.7 \pm 0.7$ and $-0.4 \pm$ 0.6 , respectively. Predicted height at the end of 2 years of therapy increased to $170 \pm 8.4 \mathrm{~cm}$ for the GH group and $171 \pm 7.5 \mathrm{~cm}$ for the combined group. This study suggests that either $\mathrm{GH}$ or $\mathrm{GH}+\mathrm{GnRHa}$ can improve height predictions among patients with congenital adrenal hyperplasia with compromised heights. While both groups showed improvement over their respective control groups, data from this study do not provide a basis to determine whether combination therapy is better than $\mathrm{GH}$ alone. 


\section{Chronic Primary Hypothyroidism}

It is well known that children with hypothyroidism and severe short stature do not usually experience full catchup growth [28]. This is particularly true among children diagnosed in late childhood or at early pubertal ages [29]. Concomitant with catch-up growth, puberty may begin and proceed at a rapid rate, together with rapid skeletal age maturity that prevents attainment of TH. GnRHa can be used to delay the rapid pubertal progression and advance in BA [30], although addition of GH may be needed to achieve TH. It is unclear, based upon case reports, whether this combination therapy is adequate, particularly if diagnosis is delayed $[31,32]$.

\section{Normal Puberty and Short Stature}

The NCGS registry data for the combined use of GH and GnRHa were published in 1999 [15]. Patient categories included girls with GHD and ISS, with or without CPP. Both the group with CPP (including those with either GHD or ISS) and those with normal puberty (also including those with either GHD or ISS) had significant increases in near adult height of $5.4 \pm 4.3$ and $3.0 \pm$ $6.1 \mathrm{~cm}$, respectively. Among the girls who did not have precocious puberty, duration of $\mathrm{GH}$ treatment was the most important variable predictive of height gain.

Two groups of 12 girls with ISS were treated for a mean of 4.5 to 5.0 years with either $\mathrm{GH}$ or $\mathrm{GH}+\mathrm{GnRHa}$ [33]. The two groups were of comparable age, with skeletal age delay, and with PAHs considerably less than THs. All patients were at Tanner stages 2 or 3 of puberty and GH responses to provocative testing were greater than $10 \mathrm{~g} / \mathrm{l}$. Both groups reached an adult height significantly greater than their pre-treatment PAH. For the combined therapy group, the gain in adult height over pre-treatment $\mathrm{PAH}$ was $10 \pm 2.9 \mathrm{~cm}$; height SDS reached $-0.5 \pm 1.0$, and the $\mathrm{TH}$ was significantly exceeded. For the GH group, the gain in adult height over pre-treatment $\mathrm{PAH}$ was $6.1 \pm$ $4.4 \mathrm{~cm}$, height SDS did not change significantly and $\mathrm{TH}$ was not reached. The authors suggest that the combination of GH and GnRHa is more effective in improving adult height than GH alone in girls with ISS, early or normal onset of puberty, diminished PAH and $\mathrm{TH}$.

\section{Aromatase Inhibitors and Oestrogen Receptor Blockers}

There are two categories of drugs that could potentially reduce the target effects of oestrogen. One involves antioestrogens that bind to the oestrogen receptor and interfere with receptor-mediated transcriptional events. These include the selective oestrogen receptor modulators that can have oestrogen agonist activity in some tissues and oestrogen antagonist activity in other tissues. The second category includes the aromatase inhibitors that block the rate-limiting step in the synthesis of oestradiol involving the conversion of androgens to oestrogens. Both categories have potential clinical uses [34], although little is known about their impact on bones, both in terms of bone growth and maintenance of bone integrity.

The primary stimulation of skeletal maturity is via oestradiol, so uses of aromatase inhibitors and anti-oestrogens are being considered [35]. Clinical studies are being conducted in males to determine whether the use of aromatase inhibitors [36] may delay advance of BA, allowing more time for growth without suppressing pubertal development [37]. Aromatase inhibitors may be a selective tool to delay skeletal age maturation without suppressing sex steroids, as with GnRHa [38]. A better understanding of the physiological effects of these compounds in both animals and humans, and long-term safety studies in man, must be done before such therapy can be considered for clinical purposes [39].

\section{Summary}

The data from a number of combination trials are summarized here and in another publication addressing theoretical and practical considerations [40]. GnRHa therapy slows skeletal maturation providing for more time for growth. Such therapy is often accompanied by a decelerating growth rate except in those patients who are also being treated with GH. Timely treatment of patients with CPP with GnRHa and of those with GHD with GH is associated with normal adult heights. If puberty has progressed so that growth potential is reduced, however, carefully monitored combination therapy may lead to reclaimed height and better adult heights. Some outcome information suggests that, in some situations, primary therapy using $\mathrm{GH}$ alone or GnRHa alone may be adequate to reach expected adult heights. 


\section{References}

1 Blizzard RM, Joyce S, Mitchell T, Johanson AJ, Libber SM, Plotnick LP, Migeon CJ: Psychosocial impact of long-term growth hormone therapy; in Raiti S, Tollman R (eds): Human Growth Hormone. New York, Plenum Publishing Corporation, 1986, pp 93-106.

2 Frasier SD, Lippe BM: Clinical review 11: the rational use of growth hormone during childhood. J Clin Endocrinol Metab 1990;71:269_ 273.

3 Kappy M, Stuart T, Perelman A, Clemons R: Suppression of gonadotropin secretion by a long-acting gonadotropin-releasing hormone analog (leuprolide acetate, Lupron Depot in children with precocious puberty. J Clin Endocrinol Metab 1989;69:108-109.

4 Lee PA, Page JG: Effects of leuprolide in the treatment of central precocious puberty. J Pediatr 1989;114:321-324.

5 Lee PA, Witchel SF: The influence of estrogen on growth. Curr Opin Ped 1997;9:431-436.

6 Bourguignon JP: Growth and timing of puberty: reciprocal effects. Horm Res 1991;36:1315.

7 Karlberg J, Fryer JG, Engstrom I, Karlberg P: Analysis of linear growth using a mathematical model. II. From 3 to 21 years of age. Acta Pediatr Suppl 1987;337:12-29.

8 Lee PA: GnRH analogues in the management of precocious puberty; in Lunenfeld B (ed): GnRH Analogues: The State of the Art 2001. Pearl River, New York, Parthenon Publishing Group, 2002, pp 97-110.

9 Attie KM, Ramirez NR, Conte FA, Kaplan SL, Grumbach MM: The pubertal growth spurt in eight patients with true precocious puberty and growth hormone deficiency: evidence for a direct role of sex steroids. J Clin Endocrinol Metab 1990;71:975-983.

10 Stanhope R, Uruena M, Hindmarsh P, Leiper A, Brook C: Management of growth hormone deficiency through puberty. Acta Paediatr Scand Suppl 1991;372:47-52.

11 Hibi I, Tanaka T, Tanae A, Kagawa J, Hashimoto N, Yoshizawa A, Shizume K: The influence of gonadal function and the effect of gonadal suppression treatment on final height in growth hormone $(\mathrm{GH})$ treated $\mathrm{GH}$-deficient children. J Clin Endocrinol Metab 1989;69: 221-225.

12 Leiper A, Stanhope R, Preece M, Grant D, Chessells J: Precocious and early puberty and growth failure in girls treated for acute lymphoblastic leukemia. Horm Res 1988;30:72-76.

13 Thomas BC, Stanhope R, Leiper AD: Gonadotropin releasing hormone analogue and growth hormone therapy in precocious puberty and premature puberty following cranial irradiation for acute lymphoblastic leukaemia. Horm Res 1993;39:2-9.
14 Cara J, Kreiter M, Rosenfield R: Height prognosis of children with true precocious puberty and growth hormone deficiency: effect of combination therapy with gonadotropin releasing hormone agonist and growth hormone. J Pediatr 1992;120:709-715.

15 Kohn B, Julius JR, Blethen SL: Combined use of growth hormone and gonadotropin-releasing hormone analogues: the national cooperative growth study experience. Pediatrics 1999;194: 1014-1018.

16 Adan L, Souberbielle JC, Zucker JM, PierreKahn A, Kalifa C, Brauner R: Adult height in 24 patients treated for growth hormone deficiency and early puberty. J Clin Endocrinol Metab 1997;82:229-233.

17 Stanhope R, Brooke CG: The effect of gonadotropin releasing hormone analogue on height prognosis in growth hormone deficiency and normal puberty. Eur J Pediatr 1988;148:200202.

18 Saggese G, Cesaretti G, Andreani G, Carlotti $\mathrm{C}$ : Combined treatment with growth hormone and gonadotropin-releasing hormone analogues in children with isolated growth hormone deficiency. Acta Endocrinol 1992;127: 307-312.

19 Mericq MV, Eggers M, Avila A, Cutler GB Jr, Cassorla F: Near final height in pubertal growth hormone $(\mathrm{GH})$-deficient patients treated with $\mathrm{GH}$ alone or in combination with luteinizing hormone-releasing hormone analog: results of a prospective, randomized trial. J Clin Endocrinol Metab 2000;85:569-573.

20 Mul D, Oostdijk W, Waelkens JJ, Schulpen TW, Drop SL: Gonadotrophin releasing hormone agonist treatment with or without recombinant human $\mathrm{GH}$ in adopted children with early puberty. Clin Endocrinol (Oxf) 2001;55: 121-129.

21 Lee PA: Pubertal growth in $\mathrm{GH}$ deficient males: corrected by early GH therapy, but not GnRH analogue. Pediatric Academic Society, Pediatr Res 2002;51:119A(696).

22 Oostdijk W, Drop S, Odink R, Hummelink R, Partsch C, Sippell W: Long-term results with a slow-release gonadotropin-releasing hormone agonist in central precocious puberty. Acta Paediatr Scand Suppl 1991;372:39-45.

23 Pasquino AM, Municchi G, Purcarelli I, Segni M, Mancini MA, Troiani S: Combined treatment with gonadotropin-releasing hormone analog and growth hormone in central precocious puberty. J Clin Endocrinol Metab 1996; 81:948-951.

24 Pasquino AM, Pucarelli I, Segni M, Matrunola M, Cerrone F: Adult height in girls with central precocious puberty treated with gonadotropinreleasing hormone analogues and growth hormone. J Clin Endocrinol Metab 1999;84:449_ 452.

25 Pucarelli I, Segni M, Ortore M, Moretti A, Iannaccone R, Pasquino AM: Combined therapy with GnRH analog plus growth hormone in central precocious puberty. J Pediatr Endocrinol Metab 2000;13:811-820.
26 Mul D, Wit M, Oostdijk W, Van den Broeck J: The effect of pubertal delay by GnRH agonist in $\mathrm{GH}$-deficient children on final height. J Clin Endocrinol Metab 2001;86:4655-4656.

27 Quintos JB, Vogiatzi MG, Harbison MD, New MI: Growth hormone therapy alone or in combination with gonadotropin-releasing hormone analog therapy to improve the height deficit in children with congenital adrenal hyperplasia. J Clin Endocrinol Metab 2001;86:1511-1517.

28 Rivkees SA, Bode HH, Crawford JD: Longterm growth in juvenile acquired hypothyroidism: the failure to achieve normal adult stature. N Engl J Med 1988;318:599-602.

29 Pantsiouou S, Stanhope R, Uruena M, Preece MA, Grant DB: Growth prognosis and growth after menarche in primary hypothyroidism. Arch Dis Child 1991;66:838-840.

30 Lee PA: GnRH analogue in primary hypothyroidism among pubertal girls: a novel use to preclude loss of adult height. Gynecol Endocrinol 1996;10(Suppl 1):76.

31 Miyazaki R, Yanagawa N, Higashino H, Kobayashi Y: LHRH analogue and growth hormone did not improve the final height of a patient with juvenile hypothyroidism accompanied by precocious puberty. Arch Dis Child 2000;83:87.

32 Minamitani K, Murata A, Ohnishi H, Wataki K, Yasuda T, Niimi H: Attainment of normal height in severe juvenile hypothyroidism. Arch Dis Child 1994;70:429-430.

33 Pasquino AM, Purarelli I, Roggini M, Segni M: Adult height in short normal girls treated with gonadotropin-releasing hormone analogs and growth hormone. J Clin Endocrinol Metab 2000;85:619-622.

34 Santen RJ: To block estrogen's synthesis or action. That is the question. J Clin Endocrinol Metab 2002;87:3007-3012.

35 Rochira V, Balestrieri A, Madeo B, Spaggiari A, Carani C: Congenital estrogen deficiency in men: a new syndrome with different phenotypes; clinical and therapeutic implications in men. Mol Cell Endocrinol 2002;31:19-28.

36 Mauras N: Author's response: aromatase inhibitors in pubertal boys - clinical implications. $\mathrm{J}$ Clin Endocrinol Metab 2001;86:1837-1838.

37 Grumbach MM, Auchus RJ: Estrogen: consequences and implications of human mutations in synthesis and action. J Clin Endocrinol Metab 1999;84:4677-4694.

38 Mauras N, O'Brien KO, Klein KO, Hayes V: Estrogen expression in males: metabolic effects. J Clin Endocrinol Metab 2000;85:23702377.

39 Rochira V: Aromatase inhibitors in pubertal boys: clinical implications. J Clin Endocrinol Metab 2001;86:1836-1838.

40 Walvoord EC, Pescovitz OH: Combined use of growth hormone and gonadotropin-releasing hormone analogues in precocious puberty: theoretic and practical considerations. Pediatrics 1999;104:1010-1014. 